\title{
A Gynandromorph in Drosophila Produced by Double Fertilization
}

\author{
By \\ Richard Goldschmidt \\ University of California, Berkeley, California
}

It is well known that the majority of gynandromorphs in Drosophila are derived from XX-eggs from which at some stage one $X$ has been eliminated. But there are a few cases on record in which the distribution of marking genes to the male and female parts of the body lead to the assumption that gynandromorphism has been produced by double fertilization of a binucleated egg by two sperms. These cases have been completely reviewed by L. V. Morgan and C. Stern. As a matter of fact, such cases cannot be regarded as doubtful occurrences any more, since Goldschmidt and Katsuki proved the occurrence of hereditary gynandromorphism in the silkworm (also one case in Lymantria) on the basis of double fertilization of the female pronucleus and one of the reduction nuclei, the socalled Richtungskern. In Drosophila, however, this type seems to be rather rare, which justifies the description of a new case. It closely resembles two cases described by L. V Morgan (p. 229), but is superior to them in one feature of the analysis.

This gynandromorph appeared in a backcross of a female with attached X-chromosomes both carrying yellow and autosomes marked by the genes bw (brown II), e (sooty III) and ey (eyeless IV). The father of the backcross was a hybrid between a female of the same constitution and a male carrying the gene $r$ (rudimentary) within the $\mathrm{X}$-chromosome. The gynandromorph is almost completely bilateral: left male, sooty and rudimentary; right female, yellow, normal wings. The lines of demarcation between male and female parts are very sharp in the anterior part of the body. In the thorax and scutellum the black-yellow border line coincides exactly with the median. But the color of the tip of the abdomen is male, the genital armature mixed.

There can be no doubt that the female half contains the $\widehat{\mathrm{XX}}$ from the mother. But as none of the autosomal recessive genes are visible, the sperm responsible for the female parts must have contained the normal allelomorphs of these genes and in addition the Y-chromosome. There can further be no doubt that the male parts contained the paternal X-chromosome with the rudimentary gene. As the male half was sooty it must have received from both 
parents the gene $\mathrm{e}^{\mathrm{s}}$, i.e., o nucleus $\mathrm{Y}$ bw $\mathrm{e}^{\mathrm{s}}$ ey $\mathrm{X}$ or nucleus $\mathrm{v}^{\mathrm{r}}+\mathrm{e}^{\mathrm{s}}+$ Therefore this part of the body as well as the other must be the product of fertilization, but with a different type of sperm. This proves that two sperm cells have fertilized two egg nuclei and, further, that these two nuclei were the product of a reduction division: $\widehat{\mathrm{XXY}} \rightarrow \widehat{\mathrm{XX}}+\mathrm{Y}$. (There would be the alternative of haploid development of one sperm nucleus; thus far nothing points to the possibility of such an event.) This was, then, the origin of the gynandromorph:

Egg N.I. $Y$ bw $e^{s}$ ey $x$ sperm $X_{(r)}+e^{s}+$

Egg N. II. $\widehat{\mathrm{XX}}$ bw $\mathrm{e}^{\mathrm{s}}$ ey $\mathrm{x}$ sperm $\mathrm{Y}+++$.

\section{Literature}

Goldschmidt, R. (1923) Ein weiterer Beitrag zur Kenntnis des Gynandromorphismus. Biol. Cbl. 43.

u. Katsuki, K. (1927-31) Erblicher Gynandromorphismus und somatische Mosaikbildung bei Bombyx mori L. I-IV. Biol. Cbl. 47, 48, 51.

Morgan, L. V. (1929) Composites of Drosophila melunogaster. Carnegie Inst. Washington Publ. 399.

Stern, C., u. Sekiguti, K. (1931) Analyse eines Mosaikindividuums bei Drosorhila melanogaster. Biol. Cbl. 51. 